\title{
MAGNETISMO ESPIRITUAL: TORIBIO ROMO SUS RELIQUIAS Y LA EXPANSIÓN TERRITORIAL DEL CULTO.
}

- CÉSAR EDUARDO MEDINA GALLO ${ }^{1}$

RESUMEN : LA IMPLANTACIÓN DEL CULTO A LAS RELIQUIAS Y A LOS SANTOS POR PARTE DEL COLONIALISMO ESPAÑOL, TRAJO CONSIGO UN MODELO DE CREENCIA PARTICULAR EN EL VIRREINATO DE LA NUEVA ESPAÑA, EL CUAL SE REFORZÓ POSTERIOR A ÉSTE PERIODO Y LA CONFORMACIÓN DE LO QUE HOY SE IDENTIFICA COMO MÉXICO. EN EL CASO DE LA REGIÓN ALTOS DE JALISCO, UBICADA AL OCCIDENTE DEL PAÍS; LA IGLESIA CATÓLICA JUGÓ UN PAPEL DETERMINANTE EN LA CONFORMACIÓN SOCIO-CULTURAL DE LA POBLACIÓN QUIEN LA DOTÓ DE UNA IDENTIDAD QUE SE DIFERENCIA A OTRAS ZONAS Y REGIONES DE LA NACIÓN. ULTERIOR A LA REVOLUCIÓN MEXICANA (1910-1921) SURGEN UNA SERIE DE LEYES ANTICLERICALES QUE RECONOCEN LA SUPERIORIDAD JURÍDICA DEL ESTADO SOBRE LA IGLESIA, ESTO DERIVÓ EN UN CONFLICTO ENTRE INSTITUCIONES QUE TERMINÓ EN UN LEVANTAMIENTO ARMADO POR LOS HABITANTES DE LOS ALTOS DE JALISCO Y EL CENTROOCCIDENTE DE MÉXICO, EN ESTE PERIODO (1926-1929), SE GESTAN CULTOS POPULARES, DONDE SE DESTACA A TORIBIO ROMO, SACERDOTE ASESINADO DURANTE EL CONFLICTO Y DE QUIEN LA POBLACIÓN LOCAL OBTIENE LAS RELIQUIAS PARA SU VENERACIÓN; AÑOS DESPUÉS LA INSTITUCIÓN CATÓLICA OTORGA LA CATEGORÍA DE SANTO (AÑO 2000). POSTERIOR A ESTE HECHO, SE INICIAN EL AUMENTO EN LOS DESPLAZAMIENTOS HACIA LA LOCALIDAD DE SANTA ANA DE GUADALUPE, PARA LA VENERACIÓN DE LAS RELIQUIAS, Y LOS FLUJOS HAN CRECIDO EN ESCALAS GEOGRÁFICAS HASTA CONVERTIRSE EN INTERNACIONALES, DEBIDO AL ALTO ÍNDICE DE MIGRACIÓN HACIA ESTADOS UNIDOS.

PALABRAS CLAVE: MAGNETISMO ESPIRITUAL, RELIQUIAS, SANTOS, TORIBIO ROMO. 
Introducción

El presente trabajo muestra el aumento en el alcance territorial de los desplazamientos con motivaciones religiosas al santuario dedicado a Toribio Romo. Sacerdote originario de la localidad de Santa Ana de Guadalupe quien fue asesinado durante el conflicto cristero en 1928, en ese momento la población inicia un culto popular a las reliquias que se obtuvieron en los momentos posteriores a su muerte, estos elementos son reconocidos como el puente material y terrenal entre el ser humano y la divinidad. En este sentido, el culto a Toribio Romo ha presentado un aumento en los desplazamientos hacia la localidad. Una de las cuestiones principales, es el reconocimiento de Santo por parte de la institución católica, y el culto se ha difundido y aceptado en las áreas y regiones cercanas, que posteriormente efectúan el viaje para el encuentro con el santo, esto ha derivado en un aumento en las escalas de los desplazamientos, los cuales se explicarán a continuación.

\section{Reliquias como elemento de magnetismo espiritual}

En la literatura, los viajes emprendidos hacia santuarios en las distintas religiones mundiales se identifican como peregrinaciones ${ }^{2}$ El estudio de tales manifestaciones desde la perspectiva geográfica ha presentado un gran interés al enfocarse en la dimensión espacial de las mismas. En años recientes, geógrafos han clasificado peregrinaciones y lugares sagrados, donde se examina su distribución, se analiza su dimensión temporal y se manifiestan cambios metodológicos, anteriormente encuadrados en marcos descriptivos, pero actualmente se han realizado estudios empíricos, analíticos e interpretativos. Es de gran importancia e interés el estudio de las peregrinaciones, ya que como menciona Vukonić (1996) son comunes a todas las religiones, pero esta idea puede ser cuestionada, ya que por ejemplo, el protestantismo no presenta peregrinaciones dentro de sus prácticas.

Para entender la dinámica de las peregrinaciones, es necesario identificar los elementos que las originan y las posibilitan, en ese sentido; Preston (1992) genera un concepto llamado magnetismo espiritual el cual es definido simplemente como: "el poder de los santuarios para atraer devotos" (Ibíd:: 33). Éste no es una cualidad sagrada intrínseca a los orígenes misteriosos que se irradien objetivamente de los lugares de peregrinación, más bien, el magnetismo espiritual deriva de conceptos y valores humanos, vía histórica, geográfica, social, y otras fuerzas que se unen en los centros de peregrinación.

Explicaciones populares de las atribuciones del magnetismo espiritual 
atribuidas al centro sagrado son válidas desde el punto de vista de los participantes. No se puede descuidar las variables extrínsecas que hacen que un santuario de peregrinación sea atractivo. Los centros de peregrinación están dotados con magnetismo espiritual en asociación con: 1) curas milagrosas, 2) aparición de seres sobrenaturales, 3) Geografía Sagrada y 4) dificultad de acceso (Cuadro 1).

No todos los centros de peregrinación están dotados igualmente con las cuatro variables que contribuyen al desarrollo del magnetismo espiritual.

Cuadro 1. Elementos del magnetismo espiritual

\begin{tabular}{|c|c|c|c|}
\hline 1) Curas milagrosas & $\begin{array}{l}\text { 2) Aparición de seres } \\
\text { sobrenaturales }\end{array}$ & $\begin{array}{l}\text { 3) Geografía } \\
\text { sagrada }\end{array}$ & 4) Dificultad de acceso \\
\hline $\begin{array}{l}\text { Arroyos sagrados, } \\
\text { aguas termales y otras } \\
\text { fuentes de agua } \\
\text { natural } \\
\text { frecuentemente son } \\
\text { asociados } \\
\text { curaciones. } \\
\text { Atraen gran número } \\
\text { de peregrinos a los } \\
\text { centros sagrados. } \\
\text { Algunos incluyen la } \\
\text { presunta intervención } \\
\text { de una deidad o un } \\
\text { santo. Estos lugares } \\
\text { tienen gran atracción } \\
\text { aún en la actualidad } \\
\text { con un mayor } \\
\text { desarrollo de la } \\
\text { medicina moderna. }\end{array}$ & $\begin{array}{l}\text { Es creído que las } \\
\text { deidades hablan } \\
\text { directamente con las } \\
\text { personas quienes, como } \\
\text { medios del encuentro } \\
\text { divino, entregan el } \\
\text { mensaje o revelan las } \\
\text { leyes sagradas. Los } \\
\text { sitios asociados con las } \\
\text { apariciones son } \\
\text { atribuidos con fuertes } \\
\text { poderes místicos. } \\
\text { El magnetismo } \\
\text { espiritual es aumentado } \\
\text { en estos lugares por la } \\
\text { ejecución de ritos de } \\
\text { renovación }\end{array}$ & $\begin{array}{l}\text { En aquellas } \\
\text { tradiciones donde } \\
\text { la Tierra es } \\
\text { asociada con } \\
\text { fuertes } \\
\text { sentimientos } \\
\text { religiosos, el } \\
\text { magnetismo } \\
\text { espiritual es } \\
\text { fuertemente ligado } \\
\text { a la geografía } \\
\text { sagrada. } \\
\text { No siempre está } \\
\text { definido en } \\
\text { términos de las } \\
\text { características } \\
\text { dramáticas del } \\
\text { terreno. }\end{array}$ & $\begin{array}{l}\text { Algunos sitios de } \\
\text { peregrinación alcanzan } \\
\text { un alto grado de } \\
\text { magnetismo espiritual } \\
\text { porque ellos son difíciles } \\
\text { de alcanzar debido a los } \\
\text { factores intrínsecos o } \\
\text { extrínsecos. Un santuario } \\
\text { localizado en un lugar } \\
\text { precario alcanza algo de } \\
\text { su magnetismo espiritual } \\
\text { de los peligros } \\
\text { "intrínsecos" asociados } \\
\text { con el viaje de } \\
\text { peregrinación en sí } \\
\text { mismo. La peregrinación } \\
\text { requiere sacrificio, un } \\
\text { ingrediente importante } \\
\text { para intensificar el } \\
\text { magnetismo espiritual }\end{array}$ \\
\hline
\end{tabular}

Fuente: elaboración con base en Preston, 1992. 
Algunos centros atraen gran número de peregrinos aunque estén asociados con sólo algunos de ellos. Así, el autor expresa que las cuatro variables asociadas con el magnetismo espiritual no son exhaustivas, existen otros factores que deben ser tomados en cuenta e investigados, como el rol de la identidad nacional en la formación de dicho magnetismo, como muchos santuarios católicos marianos como Czestochowa (Polonia), Guadalupe (México), Copacabana (Bolivia), entre otros. (Preston, 1982, citado en Preston, 1992). Asimismo, la presencia de reliquias en un santuario puede aumentar el magnetismo espiritual, incluso, se pueden identificar como un elemento adicional a los propuestos por Preston, por la carga simbólica que se les atribuye por parte de los creyentes y a su vez es una práctica arraigada desde el proceso de institucionalización cristiana.

De acuerdo con lo anterior, Durante el siglo IV, cuando la iglesia cristiana se consolidó como institución y definió sus dogmas básicos por ejemplo, se emplea una división territorial por diócesis y la expansión del latín como lengua litúrgica. En esta época, los obispos católicos comenzaron a trasladar los huesos de los mártires, víctimas de las persecuciones de los siglos anteriores, desde las catacumbas hacia hermosos templos construidos ex profeso para contenerlos. Los cuerpos de los mártires, de los eremitas y de los obispos se convirtieron en reliquias y las tumbas que los contenían se volvieron santuarios de peregrinación, lugares donde se tocaban el cielo y la tierra (RUBIAL, 1998).

Esta religión institucionalizada $\mathrm{y}$ jerarquizada que comenzaba a rendir culto a una élite de seres excepcionales que vivían en un cielo palaciego, como cortesanos alrededor de la figura imperial de Cristo. Los santos se convirtieron en patronos, al igual que la aristocracia terrateniente que vinculaba su patronazgo a amplias capas de la población; se transformaron en compañeros invisibles, en los amigos y protectores contra los males del mundo, en los intermediarios entre Dios y el ser humano (Ibíd.). Se estableció un puente entre las religiones antiguas y el nuevo monoteísmo; el politeísmo pagano encontró su sucesor en el santoral cristiano.

De las reliquias se hizo depender la prosperidad de una región y sobre ella los vasallos juraban fidelidad a sus señores; la proliferación de templos monacales $\mathrm{y}$ parroquiales hizo necesario conseguir restos mortales de santos, especialmente mártires, para poder consagrar los altares, por otro lado, las reliquias fueron para los monasterios una potente herramienta para mantener la preeminencia regional frente a los señores laicos que pretendían absorberlos (RUBIAL, op. cit.).

Todas estas experiencias de convivencia, de asimilación, de persecución y de rechazo, paganismo y religiosidad popular tuvieron a partir del siglo XVI un 
nuevo campo de acción, pero ahora fuera Europa. La implantación del cristianismo en América y el sometimiento a él de las civilizaciones indígenas dieron a la iglesia la posibilidad de poner en práctica la experiencia acumulada de siglos, aunque hicieron también el nacimiento de nuevas situaciones en los campos del sincretismo religioso.

Contexto histórico, político y sociocultural para la formación del culto a Toribio Romo

La región de los Altos de Jalisco ${ }^{3}$ se ubicaba dentro de la demarcación territorial colonial denominada Nueva Galicia y, debido a su posición geográfica, es un paso obligado para comunicar Zacatecas con las ciudades de México y Guadalajara. Como resultado, la apertura de comunicaciones en el área fue muy temprana, por la necesidad de establecer vías de comunicación con la rica zona minera de Zacatecas. Los primeros pueblos de la zona central alteña surgieron como postas de la diligencia que comunicaba la ruta México-QuerétaroLeón-Guadalajara, y de la ruta que de León seguía hacia Zacatecas (OROZCO, 1992).

Cada pueblo tendría sus santos patronos y profesarían una especial devoción hacia una Virgen en particular. Por tanto, las manifestaciones religiosas, como las fiestas del santo patrono o de la Virgen, calaron muy pronto la mentalidad popular religiosa. La tradición occidental del culto a los santos y vírgenes, fue rápidamente adoptada en tierras del Nuevo Mundo y dicha herencia incluía una fuerte veneración por las imágenes, las reliquias, las visiones y los milagros, una religiosidad "ávida de visiones y hechos prodigiosos, de reliquias y de imágenes" (RUBIAL, citado en GÁLVEZ, 1996:7).

La Iglesia Católica fue de suma importancia para la fundación de la Nueva Galicia y la unificación del centrooccidente del país. Los frailes franciscanos, al mismo tiempo que evangelizaban la región, influyeron en la historia y la cultura, alimentando a los habitantes de una conciencia regional y sentimientos de superioridad (DE LA TORRE, 2002). Religión y propiedad son parte sustancial de la construcción de la vida social, según la ideología del alteño (GUZMÁN, 2002).

A partir de las fuentes documentales, se contextualizó históricamente y se reconocieron los actores que están presentes en la reproducción de la población y los elementos simbólicos que dan identidad a la región, así como las correlaciones que existen entre ellos, las cuales son; la iglesia católica, el Estado y la misma población, todas insertadas en relaciones de poder que mantienen prácticas tradicionales gestadas en el proceso colonial, que se han ido adaptando de acuerdo con el contexto económico y político. 
Este contexto no es exclusivo ni particular de los Altos, más bien responde al proceso que caracteriza la historia social y política de México. En este sentido, Fábregas (1986), quien realiza un estudio antropológico de la zona expresa que:

$$
\begin{aligned}
& \text { “... la región y el centro } \\
& \text { en un país como México } \\
& \text { son el resultado de la } \\
& \text { combinación } \\
& \text { contradictoria de las } \\
& \text { características locales no } \\
& \text { capitalistas con las } \\
& \text { exigencias del modo de } \\
& \text { producción capitalista en } \\
& \text { expansión e internándose } \\
& \text { a través de la práctica del } \\
& \text { colonialismo }
\end{aligned}
$$

(FÁBREGAS, op. cit.: 214)".

El autor explica que, desde la Colonia, la iglesia local ha sido pieza fundamental para el mantenimiento de la oligarquía, ya que ha legitimado la diferenciación social como voluntad divina.

"La iglesia facilitó el
control y la regulación
política de la población
estableciendo las bases
corporativas sobre las
que descansa la vida
ritual de los alteños".

Con diezmos e impuestos especiales, posibilitó la concentración de propiedades de la oligarquía con la cual emparentaba y tenían intereses comunes, reforzando así la estructura previamente establecida (RODRÍGUEZ y FÁBREGAS, citados en GUZMÁN 2002:37).

La iglesia mantenía una ideología religiosa que se manifestaba en un nacionalismo local, a través del cual defendía y legitimaba los intereses de la oligarquía de la que también era parte. Sobre este grupo oligarca, recaía la tradición cultural, conservando así su posición de grupo de poder. La iglesia legitimaba y "divinizaba" las diferencias sociales, así, cualquier alteración a la norma implicaba una contradicción con lo "sagrado" (FÁBREGAS, 1986, citado en GUZMÁN, 2002).

La religión en el contexto de Los Altos de Jalisco de acuerdo con Díaz (1979), se considera como un sistema de valores que llega al denominado Nuevo Mundo dentro de un contexto cultural, económico y social.

La iglesia viene integrada en una sociedad que tiene como aparato ideológico la conquista y la dominación de nuevos pueblos y nuevas tierras para ponerlas bajo el dominio de la Corona española. Los ideales de convertir hombres al cristianismo, por un lado, y extender las colonias de España, por otro, están tan íntimamente ligados que son uno sólo, de acuerdo con las estrechas relaciones existentes en los tiempos medievales, entre la Iglesia y el Estado. 
En Los Altos de Jalisco, no había grandes pueblos indígenas que convertir, pero existía la necesidad de colonizar esta región de frontera; así, se instaló cierta población española, en el marco de una estructura cultural en la que la religión aparece como un elemento integrador importante. En ese sentido, se trata de mantener y continuar una religión trasladada del Mediterráneo a una región de la Nueva Galicia. Las estructuras eclesiásticas preceden cronológicamente, en este caso, a las estatales, dando la configuración social, política, económica y cultural de la sociedad.

A finales del siglo XIX y principios del XX, dentro del contexto occidental de la formación de los estados nacionales, México buscaba crear una nación moderna, los liberales veían a la iglesia católica como freno para tal reforma, ya que ésta tenía un enorme poder simbólico que rivalizaba con quienes buscaban la consolidación del nuevo Estado.

Las Leyes de Reforma de 1855 proclamaban la autonomía del Estado frente a la iglesia, se intentaba construir un Estado-nación con la supremacía del poder civil frente al religioso (GONZÁLEZ, citado en GUZMÁN, op. cit.). Después de la revolución de 1910, el gobierno veía a la iglesia como un obstáculo para la formación de la nación moderna, por lo tanto comenzaron los intentos para desconocerle su personalidad jurídica y sus derechos como ciudadanos (DE LA TORRE, citado en GUZMÁN, op. cit.).

En el estado de Jalisco, en julio de 1918, se intentó llevar a cabo un artículo que consistía en que sólo debería haber un sacerdote por cada 5000 habitantes, previamente registrado ante la Secretaría de Gobernación. Estas dos limitaciones a la iglesia aceleraron el conflicto a fines de 1926 hacia la lucha armada. Los jerarcas católicos aceptaban la separación de la iglesia de los asuntos del Estado, pero no su subordinación, no aceptaban otro poder que no fuera el de Dios (GONZÁLEZ, citado en GUZMÁN, op. cit.). El 4 de febrero de 1926, el arzobispo Mora y Río, de México, declaró al periódico El Universal: “el episcopado, clero y católicos, no reconoceremos y combatiremos los artículos 3, 4, 27 y 130”. El presidente Calles, interpretó lo de "combatir" como un reto al gobierno, y en respuesta expulsó a sacerdotes extranjeros, cerró escuelas y conventos, a su vez la iglesia reaccionó con la suspensión del culto público (Ibíd.).

La acción anterior se llevó a cabo el 11 de junio de 1926, ante las medidas anticlericales del gobierno como una forma de protesta simbólica. Los artículos constitucionales entraron en vigor el 31 de julio y los católicos comenzaron a defender sus templos para evitar que fueran convertidos en caballerizas o cuarteles por el ejército. Pero hasta el primero de agosto reaccionaron violentamente en una contraofensiva en la que asesinaban a 
militares y funcionarios en todo el país (GONZÁLEZ, citado en GUZMÁN, op. cit.).

En este contexto, se inicia el conflicto cristero $^{4}$ en los Altos de Jalisco; Fábregas enuncia que dicho conflicto debe entenderse como el enfrentamiento entre una oligarquía regional y otra orientada hacia el Estado Nacional; plantea que el conflicto religioso era una cortina de humo que no permitía ver el enfrentamiento entre ambos grupos por el control del poder.

El hecho que detonó el conflicto en la región de los Altos fue la suspensión del culto público el 11 de junio de 1926 como protesta simbólica en respuesta a las medidas anticlericales impuestas por el gobierno.

Entre la jerarquía eclesiástica y el Estado hubo varios intentos de "arreglos" al conflicto armado. La iglesia quería deslindarse de toda responsabilidad en el movimiento armado, mientras que los gobernantes querían conservar la superioridad jurídica.

El punto nodal para la solución del conflicto fue la negociación para reanudar el culto público. Cuando la iglesia lo suspendió, de inmediato se organizó el movimiento armado, de la misma forma, en cuanto se reanudó, la lucha se suspendió de forma casi inmediata (GONZÁLEZ, citado en GUZMÁN 2002:44).

Posterior al conflicto cristero, un nuevo escenario político se conformó en las relaciones entre el Estado y la iglesia a lo que se le llamó el modus vivendi, Guzmán hace un buen recuento cronológico de los hechos que identificaron dicha relación (Cuadro 2).

Desde el tiempo de los "arreglos" que solucionaron el conflicto cristero, los jerarcas eclesiásticos "olvidaron" hechos sucedidos prohibiendo la consulta de archivos o destruyendo los documentos que tuvieran algún tipo de información (VACA, 1998). Sin embargo, los ex cristeros mantuvieron en la memoria colectiva la historia popular y el conflicto a pesar de la oposición de las autoridades eclesiales.

En algunos poblados de los Altos de Jalisco, se preserva una memoria mitificada de su pasado cristero, manteniéndose viva la Guardia Nacional Cristera cuyos miembros (ex cristeros, sinarquistas y laicos católicos) se hacen cargo de mantener viva la memoria manteniendo visibles los restos de los cristeros (DE LA TORRE, 2002:23). 
Cuadro 2. Etapas que identifican el Modus Vivendi entre la iglesia y el Estado en México (1929-1992).

\begin{tabular}{|c|c|c|}
\hline Etapa & Periodo & hechos \\
\hline Primera & $\begin{array}{c}\text { Junio de } \\
1929 \text { a } \\
\text { fines de } \\
1931\end{array}$ & $\begin{array}{l}\text { Hubo cierta tranquilidad, ambas partes cumplieron el } \\
\text { compromiso de ilegalidad tolerada. }\end{array}$ \\
\hline Segunda & $\begin{array}{c}\text { Desde } \\
1932 \text { hasta } \\
1938\end{array}$ & $\begin{array}{l}\text { Cambios en el arzobispado de México. En este periodo surgió } \\
\text { la llamada "segunda" cristiada y el movimiento Nacional } \\
\text { Sinarquista. Lázaro Cárdenas asumió la presidencia y el } \\
\text { anticlericalismo resurgió. }\end{array}$ \\
\hline Tercera & $\begin{array}{c}\text { A partir de } \\
1938 \text { hasta } \\
1970\end{array}$ & $\begin{array}{l}\text { El Estado y la iglesia comienzan a tomar posición como } \\
\text { rivales. El gobierno controlaba las manifestaciones religiosas. } \\
\text { El gobierno permitió el control de escuelas y seminarios por } \\
\text { parte de la iglesia; en escuelas se impartía doctrina y se } \\
\text { colgaban crucifijos, muchos funcionarios de gobierno tenían a } \\
\text { sus hijos en estas escuelas, buena parte de los maestros eran } \\
\text { normalistas formados en cultura anticlerical. } \\
\text { Figura de cardenales más visible en eventos públicos, había } \\
\text { una separación entre éstos y las autoridades en los actos } \\
\text { públicos, sin embargo, existía el contacto en eventos privados. }\end{array}$ \\
\hline Cuarta & $\begin{array}{l}\text { Desde } \\
1970 \text { a } \\
\text { aprox. } \\
1992\end{array}$ & $\begin{array}{l}\text { A partir del sexenio de Luis Echeverría (1970-1976) comienza } \\
\text { un trato más cordial entre instituciones, se pasó de las } \\
\text { relaciones secretas a las discretas. } \\
\text { El ex presidente Adolfo López Mateos fue el primer alto } \\
\text { funcionario que visitó un Papa, Paulo VI, se relacionaba con } \\
\text { los jerarcas eclesiásticos de cada país que visitaba. } \\
\text { A finales de 1973, Echeverría tenía intenciones de visitar al } \\
\text { Papa, pero Roma no aceptó porque no había relaciones } \\
\text { oficiales, también intentó traer al Papa a la inauguración de la } \\
\text { nueva Basílica de Guadalupe, que se terminó de construir con } \\
\text { inversión estatal. } \\
\text { En el sexenio de López Portillo, en 1979, el Papa Juan Pablo II } \\
\text { visitó México. El presidente lo recibió como visitante } \\
\text { distinguido al que llamó "señor" y añadió: "lo dejo con los } \\
\text { representantes de su iglesia", se inició un nuevo tipo de } \\
\text { relaciones donde las discretas y secretas eran cosa del pasado. } \\
\text { El primero de diciembre de 1988, asumió la presidencia Carlos } \\
\text { Salinas de Gortari, a la toma de posesión fueron invitados } \\
\text { jerarcas más preeminentes de la iglesia católica. Por fin quedó } \\
\text { transgredida la "separación" entre las instituciones. } \\
\text { Se restablecen lazos con el Vaticano, en 1991 en su tercer } \\
\text { informe de gobierno, Salinas de Gortari promovió la nueva } \\
\text { situación jurídica de las Iglesias. } \\
\text { El } 28 \text { de enero de } 1992 \text { se publicaron las reformas de los } \\
\text { artículos 3, 4, 24, } 27 \text { y } 130 \text { en el Diario Oficial de la } \\
\text { Federación, con estas reformas la Iglesia recuperó los espacios } \\
\text { perdidos jurídicamente, porque en la práctica ya estaban } \\
\text { recuperados. }\end{array}$ \\
\hline
\end{tabular}

Fuente: elaboración con base en Guzmán, 2002. 
La beatificación de los mártires, para González, es la estrategia de la jerarquía católica tapatía y nacional para resignificar su participación en este conflicto. Pero esta estrategia no fue homogénea ya que no hubo acuerdo para actuar en coherencia con las causas de los mártires. Éstas iniciaron en momentos diferentes bajo promotores diferentes, con algunas resistencias de parte del episcopado y de los promotores romanos. Así que se comenzaron a materializar cultos y milagros (GONZÁLEZ, 2001).

Las beatificaciones tuvieron mayor fuerza y avance en 1988, que coincide con el año en el que algunos jerarcas de la iglesia fueron invitados a la toma de posesión de Carlos Salinas. El argumento principal para beatificar fue que ninguno aprobó el levantamiento armado, por lo tanto, todos fueron victimados durante el suceso. Lo anterior liberaba a la Iglesia de toda responsabilidad de la guerra.

Toribio Romo (Figura 1) es originario de la localidad de Santa Ana de Guadalupe, Jalisco, rancho fundado en 1860. Su hermano, Román Romo, le cambió el nombre de Santa Ana de Abajo a “de Guadalupe" en el año de 1920, debido a la devoción que Toribio le tenía a esta virgen (DE LA TORRE, 1992, citado en GUZMÁN, 2002).

\section{Figura 1. Imagen de Santo Toribio Romo}

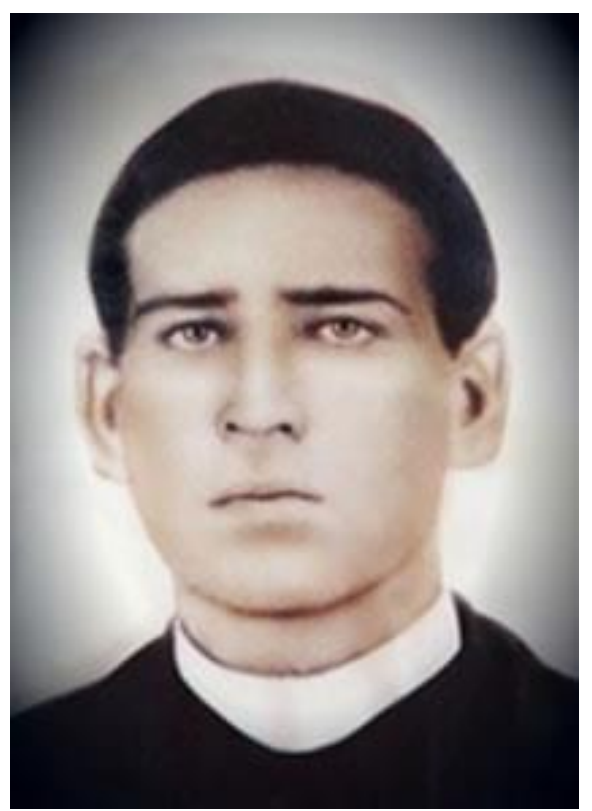

Fuente: Sitio de Santo Toribioromo, www.santotoribioromo.com, 2015 
Guzmán (2002) menciona que

“... es dificil entender $a$ simple vista el éxito del culto a Santo Toribio, pues no se puede aludir a la tradición, ya que es uno de los Santos más jóvenes apenas canonizado en el año $2000 ”$.

Tampoco a que su historia fuera única y extraordinaria, pues junto con él fueron canonizados otros 21 sacerdotes más tres laicos, quienes subieron a los altares por la misma causa: haber sido mártires durante la Guerra Cristera.

Una de las manifestaciones de la religiosidad popular es el culto a los santos, los cuales son vistos como intermediarios entre el poder supremo y la vida cotidiana. Los santos oficiales están en catedrales e iglesias principales, los santos no oficiales o populares están relegados a lugares secundarios o informales (MANDIANES CASTRO, 1989, citado en GUZMÁN, 2002). Guzmán resalta que Toribio Romo, antes de ser santificado, ya era venerado con independencia de las decisiones oficiales.

En el caso de Toribio Romo (Figura 1), el culto en torno a él se da dentro del contexto del conflicto cristero, quien es asesinado por tropas federales el 25 de febrero de 1928 en una hacienda de Tequila, Jalisco. Las reliquias se fueron configurando desde los primeros momentos después de su muerte. Los pobladores de Tequila empezaron a recoger con algodones la sangre del padre "que aún chorreaba de las heridas de las balas con que lo mataron" (ROMO, 2000). Aunque en los primeros momentos fueron los federales quienes trasladaron el cuerpo del mártir y lo arrojaron en la plaza, los habitantes de Tequila consiguieron recuperar el cadáver y lo llevaron a velar a una casa y posteriormente fue enterrado en el cementerio del lugar.

Veinte años después del asesinato del padre Toribio, en 1948, los familiares consiguieron trasladar los restos a la capilla de Santa Ana de Guadalupe, donde hasta nuestros días se encuentra el ataúd de Toribio, labrado en madera fina $\mathrm{y}$ resguardado por cristales. Las paredes laterales de la capilla siguen siendo una expresión de la crudeza que se vivió en los tiempos de la persecución religiosa. En ellas, se exhiben, en vitrinas, las reliquias del santo: las ropas ensangrentadas del mártir Toribio; el libro La liturgia de las horas, la Biblia, los algodones ensangrentados, su rosario y su morral (DE LA TORRE y GUZMÁN, 2010.).

En 1992, la Santa Sede beatificó a 25 mártires. Posteriormente, serían canonizados en el año 2000. El proceso se realizó en grupo, y venía encabezado por el Santo Cristóbal de Magallanes y "24 compañeros mártires". Sin embargo, aunque Santo Toribio desató polémica 
porque hay testimonios de que no se resignó a su martirio (fue el único que en lugar de gritar “;Viva Cristo rey!”, dijo: “;No me maten!”; y que no expresó palabra de perdón para sus verdugos -siendo requisitos fundamentales para la canonización-; no obstante, es actualmente el santo preferido por el culto popular (DE LA TORRE Y GUZMÁN, 2010).

En relación con lo anterior, y debido a que la región de los Altos de Jalisco presenta una alta migración, siendo de las más importantes del país en este sentido, se han generado relatos en torno a este sacerdote que ayuda a las personas a pasar la frontera tanto de manera legal como ilegal. A partir de ello, cada fin de semana, el santuario a Toribio es visitado por millares de mexicanos que trabajan del otro lado de la frontera. En un sólo domingo, se dan cita hasta diez mil peregrinos en busca del santo que intercede para ayudar a pasar la frontera. Todos han oído testimonios milagrosos, que multiplican el mito del "santo protector del migrante".

El fenómeno de los movimientos migratorios conlleva múltiples transformaciones económicas, políticas, sociales y culturales. La religiosidad popular es un fenómeno que no escapa a tales cambios: son los migrantes de la región alteña (además de otras regiones) quienes se han apropiado de Santo Toribio como su protector durante el trayecto, el paso de la frontera y su estancia en Estados Unidos (DE LA TORRE Y GUZMÁN, op. cit.).

La localidad de Santa Ana de Guadalupe se ubica dentro del municipio de Jalostotitlán, en el extremo suroriental del municipio; cercano a los límites con el municipio de San Miguel el Alto, marcado con las coordenadas $21^{\circ} 06^{\prime} 38^{\prime \prime} \quad \mathrm{N} \quad \mathrm{y}$ $102^{\circ} 24^{\prime} 54^{\prime \prime} \mathrm{W}$; la desviación de entrada al poblado se encuentra en la carretera que une las cabeceras municipales de los municipios antes mencionados (Figura 2).

Tradicionalmente, la localidad se dedicaba al cultivo de cebollas, pero con la sequía que sufrió la zona, así como las condiciones de abandono que vive en general el campo mexicano, la actividad económica entró en crisis y se dio un giro hacia las actividades agropecuarias, en particular el ganado vacuno para la producción de leche, que es mayoritariamente la actividad económica que se desarrolla en los Altos de Jalisco, a partir del establecimiento de empresas trasnacionales direccionadas a dicho espectro comercial. Esta ha sido la principal actividad económica de la localidad en las últimas décadas, hasta que recientemente, en la localidad de Santa Ana de Guadalupe, se llevó a cabo un cambio en todos los ámbitos de su estructura comunitaria. 
Figura 2. Ubicación geográfica de Santa Ana de Guadalupe.

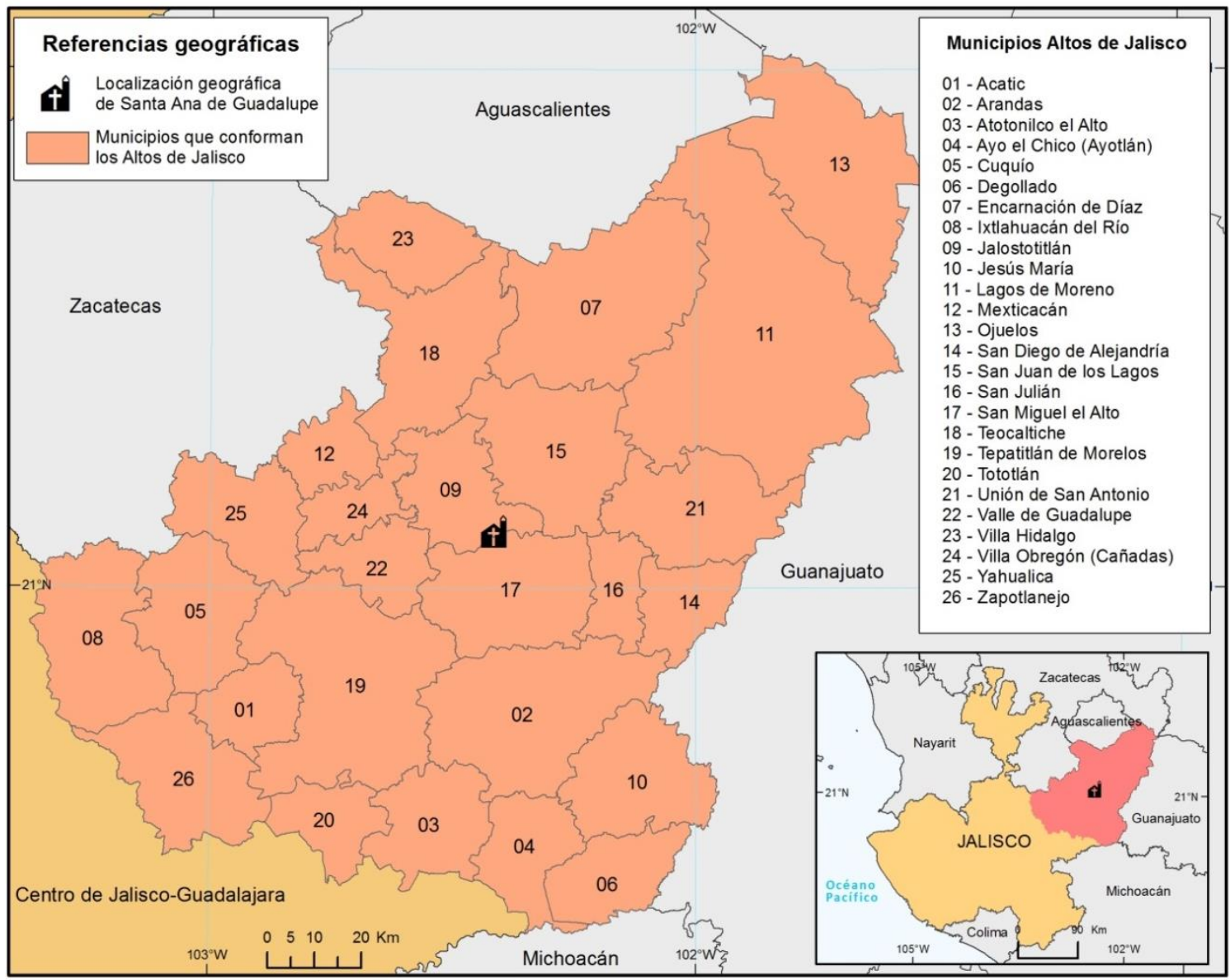

Fuente: elaboración con base en Orozco (1992).

El conocimiento sobre el ahora Santo Toribio Romo, que en sus inicios se limitaba a un culto local, se fue extendiendo poco a poco en los alrededores, lo cual generó un flujo de personas cada vez más intenso hacia la localidad, lo que derivó en una transformación territorial así como, en las actividades económicas de la localidad.

Tal vez el elemento que más ha influido es el reconocimiento de este santo como el patrono de los migrantes, que de igual manera, los estados cercanos coinciden con los que presentan los mayores índices históricos de expulsión de migrantes, específicamente hacia Estados
Unidos, lo que también ha favorecido en la expansión del conocimiento del santo y así los desplazamientos hacia este lugar.

Además de la expansión del conocimiento de este santo por ser patrono de los migrantes, se legitima su ayuda, (especialmente para aquellos que cruzan la frontera de manera indocumentada) y se toma como un elemento importante de atracción de personas que está ligado con el culto a las reliquias que se encuentran en este lugar. 
Alcance de los desplazamientos hacia

Santa Ana de Guadalupe,

Jalisco

Para cumplir tal acercamiento, el creyente se desplaza al espacio sagrado en este caso ubicado e identificado en Santa Ana de Guadalupe, por lo que el alcance en los desplazamientos hacia este sitio ha crecido en escalas geográficas, locales, nacionales e internacionales. Para constatar lo anterior, se realizó trabajo de campo en el cual se tomaron datos que evidenciaran la procedencia de los viajeros, en este sentido, para engrosar los datos se tomaron fuentes alternativas, por ejemplo los exvotos, que las personas dejan en un espacio a un costado del santuario, en algunos de ellos destacan la procedencia de la persona.
La procedencia se representa en tres distintas escalas municipal (figura 4), nacional (figura 5) e internacional (figura $6)$.

Para el caso de las procedencias municipales la Figura 4, se muestra que pertenecen a municipios cercanos geográficamente al santuario, de los estados que colindan con Jalisco, donde se ubica el santuario; como se observa, se sitúan dentro del propio estado, principalmente de los Altos donde Lagos de Moreno muestra el dato más alto de la región y uno de los más importantes de los cuales se obtuvo registro, la ciudad de Guadalajara presenta un dato fuerte de procedencias, donde se registró el mayor número de personas que se desplazaron al santuario. 
Figura 4. Santa Ana de Guadalupe: alcance municipal.

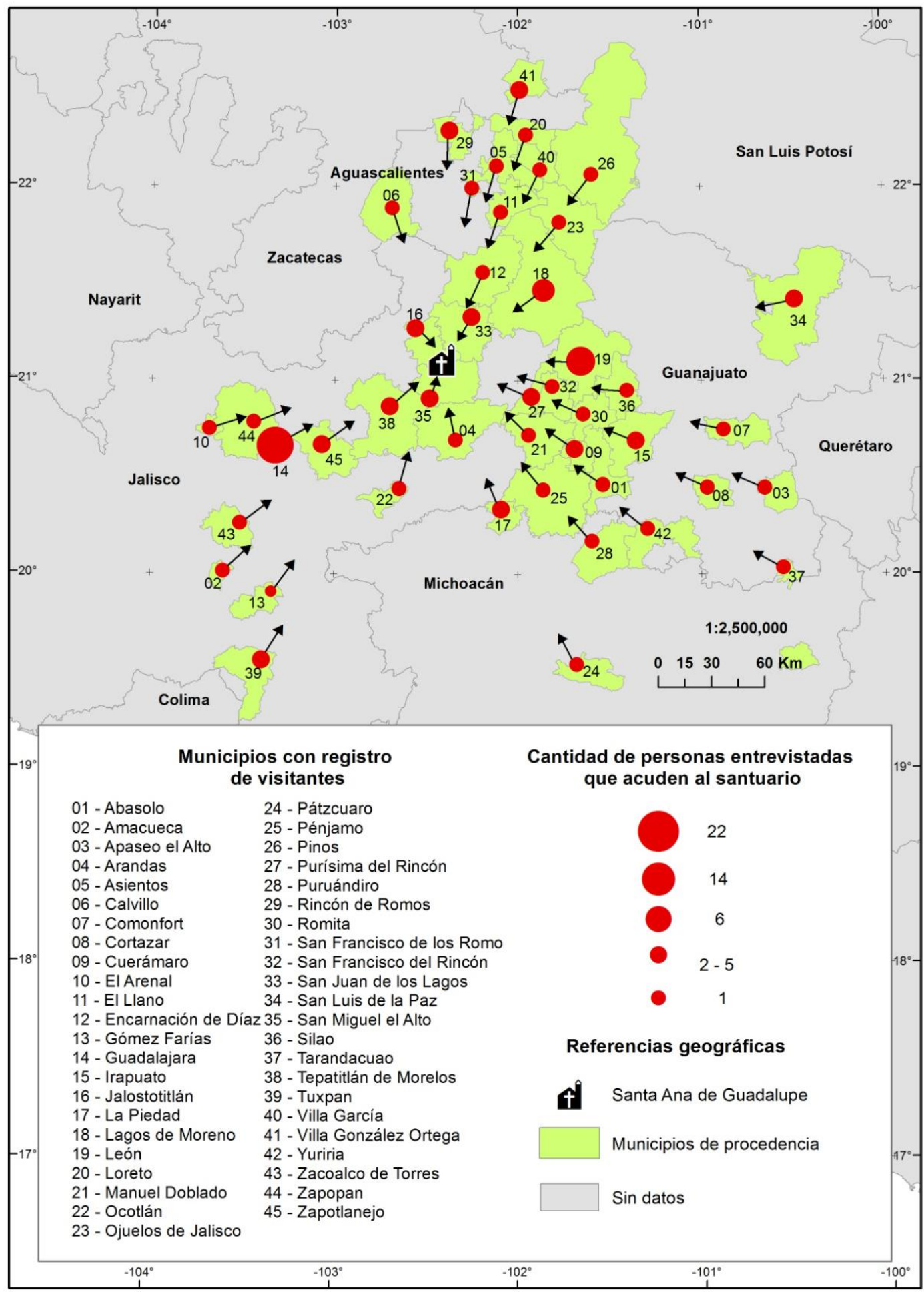

Fuente: elaborado con información obtenida en campo, abril 2014. 
Posteriormente, al interior del estado de Guanajuato se tiene una alta concentración de municipios que muestran datos de viajeros hacia el santuario, el caso de la ciudad de León es también de relevancia; es el segundo con mayor procedencia después de Guadalajara, y el número de municipios de este estado solo es superado por Jalisco.

También se tiene una cantidad importante de procedencias de municipios pertenecientes al estado de Aguascalientes $\mathrm{y}$, el número de personas que procede de cada uno de ellos se mantiene similar; no se tiene algún dato que sea relevante como el de Guadalajara en Jalisco o León en Guanajuato.

De acuerdo con los demás datos, se obtuvieron registros de municipios pertenecientes a Zacatecas, San Luis Potosí y Michoacán, donde la cantidad de personas no es tan alta como los municipios anteriores; en este sentido, el mayor número de procedencias de escala local y regional se ubica entre la región de Los Altos y los municipios cercanos tanto de Jalisco como de Guanajuato.

Los datos anteriores, obviamente, tendrán relación con el mapa siguiente donde se muestran las procedencias nacionales (Figura 5), de los estados de la república que presentan desplazamientos hacia el santuario.

En ese sentido, el dato más fuerte de procedencias nacionales es Jalisco que, como se observó anteriormente,
Guadalajara registró mayor número de viajeros, y al hacer la recopilación de registro de placas de vehículos, Jalisco apareció con mayor frecuencia, debido a que es donde se ubica el área de estudio y donde se difundió con mayor fuerza el culto en sus inicios.

En seguida se aprecia en relación con el mapa anterior, que Guanajuato resalta como el segundo estado con mayor registro de procedencias con un 53\% de los datos recopilados, y en el caso de los vehículos que arriban a la localidad, Guanajuato mostraba un gran número de autos particulares, en correspondencia de los autobuses que éstos últimos provenían de estados más alejados, también tuvo una presencia fuerte en las entrevistas realizadas y se tuvo contacto con un buen número de personas que vienen de dicho estado.

El siguiente estado con una presencia fuerte de viajeros y sobresale como un dato inesperado respecto a lo observado en el mapa de procedencias municipales, donde se esperaría que algún estado colindante con Jalisco sería el siguiente dato fuerte, es México. Este dato deriva de las entrevistas que se realizaron; en cuanto a la revisión de las placas de automóviles, también hay un registro importante de vehículos, que en su mayoría eran particulares. De igual manera, hubo una buena presencia de personas que llegaban a Santa Ana como parte de un tour. 
Figura 5. Santa Ana de Guadalupe: alcance nacional.

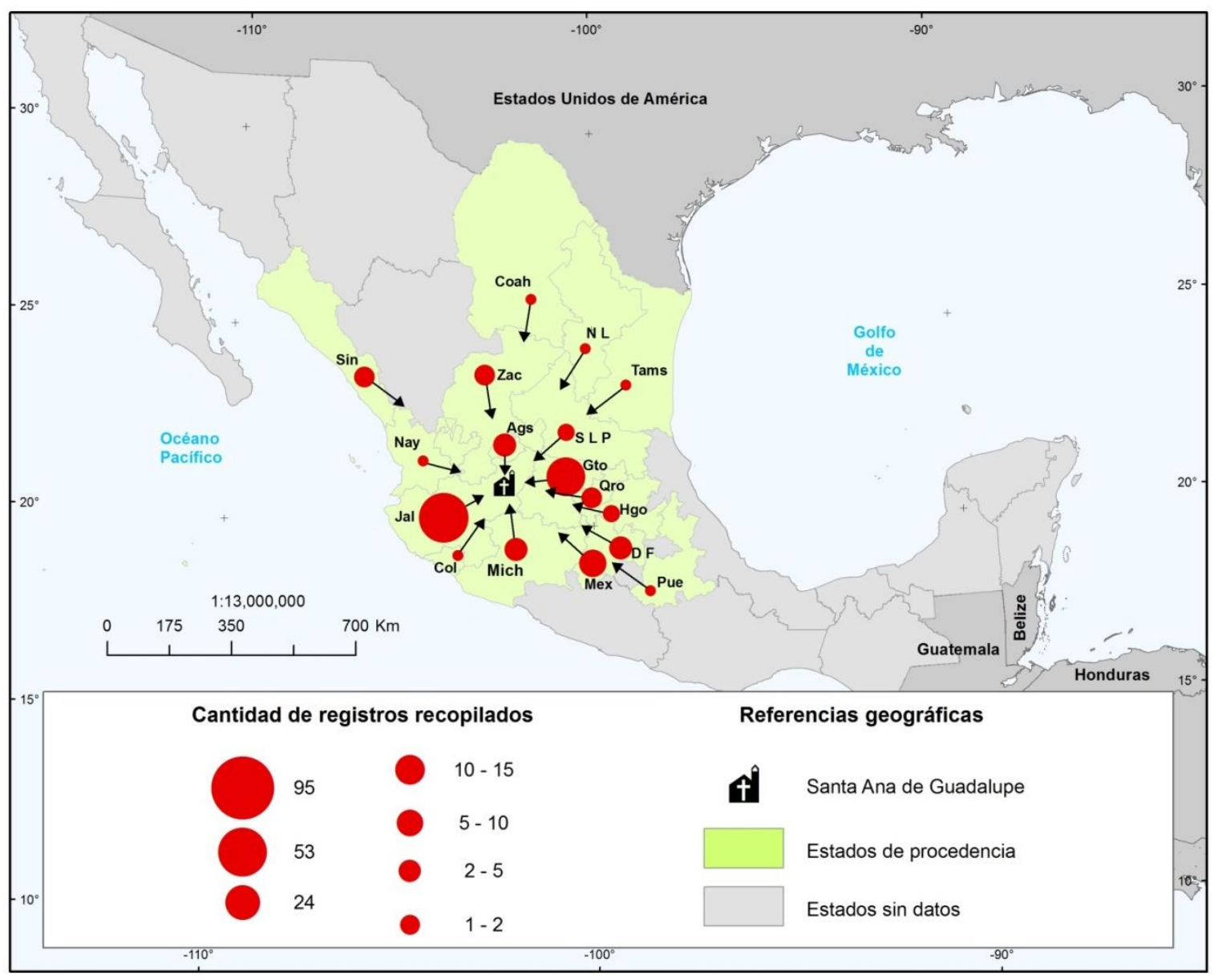

Fuente: elaborado con información obtenida en campo, abril 2014.

Los datos de mayor procedencia nacional son los estados de Jalisco, Guanajuato y México, que coinciden con los estados que presentan un alto índice de migración, en especial a Estados Unidos. Es importante hacer esta comparación ya que puede explicar cómo se extiende el conocimiento de Toribio Romo en estos sitios a quienes los vinculan como el patrono de los migrantes; en las entrevistas se destacaban constantemente los relatos y experiencias propias de los entrevistados relacionados con los movimientos migratorios y la relación con el personaje.

El Distrito Federal, Aguascalientes y Michoacán son las entidades que presentan las siguientes cantidades fuertes de registros, entre 10 y 15 , con una presencia importante en las entrevistas, también en las placas de automóviles y en los exvotos. Son interesantes esos datos, ya 
que Aguascalientes y Michoacán son estados que tienen colindancia con Jalisco; el caso de Distrito Federal muestra la expansión en la capital, que también puede ser resultado de la migración que se dio entre el campo y la ciudad y figuraba como el destino principal, posteriormente el destino principal fue Estados Unidos.

El siguiente grupo de datos los conforman los estados de Querétaro, Sinaloa y Zacatecas, todos ellos aparecieron como procedencias en las entrevistas que se realizaron; Zacatecas es uno de los principales estados de donde arriban tours que posicionan a Santa Ana de Guadalupe como uno de los destinos significativos, en el caso de las placas de vehículos también aparecieron todos éstos y en los exvotos Sinaloa y Zacatecas aparecieron como procedencias importantes.

San Luis Potosí e Hidalgo figuraron como datos en las entrevistas, donde se tuvo contacto con personas procedentes de estos estados, algunas personas que provenían de San Luis Potosí lo hicieron en tours; del estado de Hidalgo arribaron en autos particulares y no hubo una presencia importante en la revisión de los exvotos.

Finalmente, los estados de Colima, Puebla, Nayarit, Coahuila, Nuevo León y Tamaulipas aparecen como procedencias. Aunque los registros son menores, dan una impresión de como se ha presentado la expansión del culto y los consecuentes desplazamientos a Santa Ana de Guadalupe $\mathrm{y}$ el alcance que tiene el santuario a nivel nacional. Todos tuvieron presencia en las entrevistas realizadas, registro de automóviles y en la revisión de exvotos, en este grupo de datos se encuentran aquellos que presentan la mayor distancia geográfica al santuario, que como se mencionó antes, no son grandes registros pero figuran como lugares a los cuales el conocimiento del santo se ha extendido.

Se observa que la expansión se ha dado en los estados del centro-occidente del país principalmente, pero ya con una mayor presencia hacia el norte, todos aquellos estados que colindan con Jalisco y comparten un pasado histórico marcado por el conflicto cristero y en donde la imagen mitificada de los mártires ha adquirido gran fuerza, como Guanajuato, Michoacán, Colima, Aguascalientes, Zacatecas y el propio Jalisco.

Al realizar la investigación y obtener los registros por medio de las entrevistas, se contactó con personas que radican en Estados Unidos o quienes habían estado temporalmente y viajaban nuevamente a México. Hay quienes mencionaron estar en Santa Ana de Guadalupe para pedir buena fortuna para el viaje de cruce de la frontera.

En la siguiente figura (6), donde se muestran las procedencias internacionales, todas son desde Estados Unidos. Como se puede observar, el estado California es el que muestra el dato más alto, debido a que es el principal destino de los mexicanos al migrar al país del norte. Son reconocibles 
las ciudades de Los Ángeles, Sacramento y Anaheim, con gran presencia de mexicanos, donde hay barrios de personas provenientes de comunidades de Jalisco ${ }^{5}$, por esto California destaca como el principal punto de procedencia internacional.

Al realizar las entrevistas, se tuvo contacto con personas procedentes de California, una de ellas dijo ser familiar de Toribio Romo y explicaba cómo se ha dado a conocer el santo allá y que continúa en expansión; también, al revisar el registro de los exvotos, se identificó una cantidad importante procedente de este lugar. En cuanto a la revisión de las placas de los vehículos apareció registrado, pero se debe tomar en cuenta que en esta zona se encuentran gran cantidad de autos con placas de California, que fueron comprados y circulan en México, lo que deja de manifiesto la vinculación entre el área de estudio y Estados Unidos. 
Figura 6. Santa Ana de Guadalupe: alcance internacional.

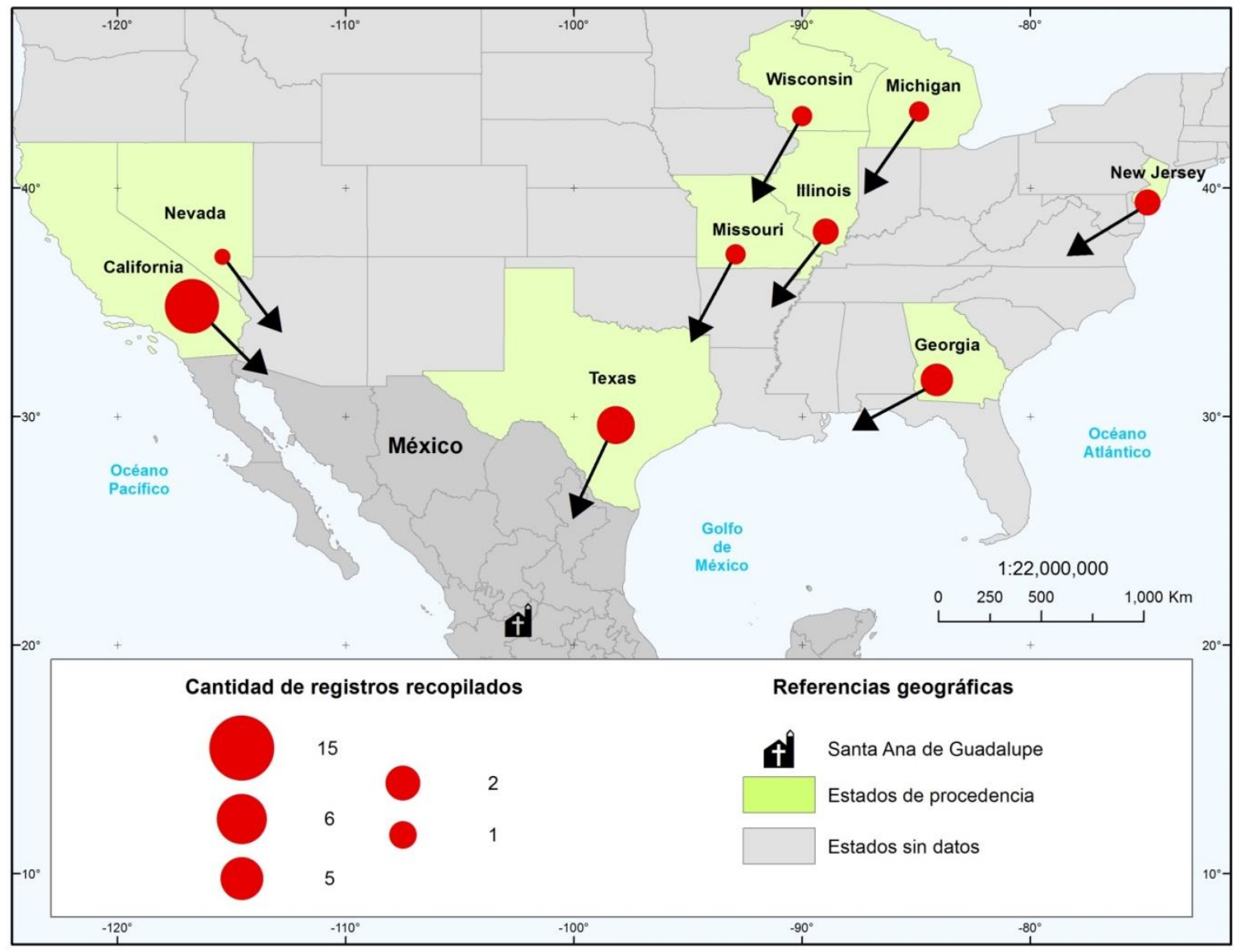

Fuente: elaborado con información obtenida en campo, abril 2014. 
Los estados que tuvieron el segundo mayor registro son Texas y Georgia, en las entrevistas se tuvo contacto con personas que viven en Georgia y era su primer visita al santuario, pero mencionan que se habla mucho de Santa Ana en su lugar de residencia, también en el registro de los exvotos aparecen como datos importantes.

Illinois y New Yersey aparecen como los siguientes en contar con mayor número de registros; en ese sentido, es porque la migración de los mexicanos ya no se limita a los estados que comparten la frontera con México, sino que se ha ido extendiendo hasta la costa este de Estados Unidos y, con ello, el culto a Toribio Romo.

Posteriormente, Michigan, Missouri y Wisconsin comparten el mismo número de registros, los cuales se obtuvieron en la revisión de los exvotos, en ellos se explicaba el vínculo con Toribio Romo y el agradecimiento por ayudar en el cruce de la frontera; esto puede considerarse con un vínculo con el fenómeno migratorio.

Finalmente, Nevada también aparece con registro de procedencia, se contactó en las entrevistas con personas que visitaron el santuario procedentes de este estado, de igual manera son originarios de Jalisco y actualmente radican en Estados Unidos.

\section{Conclusiones}

Las prácticas de culto a las reliquias son un elemento religioso católico que se institucionaliza al tiempo que la misma iglesia para "cristianizar" a las sociedades europeas de la Edad Media; se forma la idea de rendir culto a una élite de seres excepcionales que, al igual que la aristocracia terrateniente, vinculaba su patronazgo a amplias capas de la población.

En todo este contexto, se forma el culto a Toribio Romo y se ha presentado un crecimiento en la expansión geográfica del culto, en sus inicios, durante el conflicto cristero, se genera popularmente, donde las prácticas y la experiencia son locales. Con el traslado de las reliquias a Santa Ana de Guadalupe, se identifica a este sitio como el punto de encuentro al que se reconoce con magnetismo espiritual, además de la sacralización popular del lugar que conserva la visión mítica del pasado cristero. Al aumentar la relación entre la iglesia y el poder político, posibilita la denominación y la incorporación de creencias populares a la institución eclesiástica.

$\mathrm{Al}$ observar e interpretar los mapas presentados se muestra la expansión en el alcance que el santuario de Santa Ana de Guadalupe exhibe, a través del culto dirigido a Toribio Romo y las prácticas que surgen de él, como los desplazamientos por motivaciones religiosas que arriban a la localidad, se fortalecen por el contexto histórico que le da sustento y la situación 
migratoria que justifican la expansión y el

Notas

1 Licenciatura en Geografía por la Universidad Nacional Autónoma de México (UNAM).

Maestría en Geografía en la línea Sociedad y Territorio por la Universidad Nacional Autónoma de México (UNAM).

Estancia de investigación en el Nucleo de Estudos e Pesquisas sobre Espaço e Cultura (NEPEC).

Actualmente estudiante de Doctorado en Geografía en la Universidad Nacional Autónoma de México (UNAM). E-mail: cesar_gallo87@hotmail.com; gallocesar87@gmail.com

2 Para entender mejor dichas manifestaciones ver: Bhardwaj, S. (1997) y Stoddard, R. (1997).

${ }^{3}$ Ver figura 1.2

${ }^{4}$ Ver pormenores en Medina, 2011.

${ }^{5} \mathrm{Al}$ respecto se puede ver el trabajo de Hirai Shinji

Bibliografía

BHARDWAJ, S. "Geography and Pilgrimages: a review". In Sttodard, R. and A. Morinis (Ed). Sacred Places, Sacred Spaces: The Geography of Pilgrimage. GEOSCIENCE AND MAN, vol. 34. Geoscience Publications, Department of Geography and Anthropology. Lousiana State University. Baton Rouge, L.A. USA. 1997

DÍAZ, J. El movimiento cristero, sociedad y conflicto en Los Altos de Jalisco. Editorial Nueva Imagen. México. 1979

DE LA TORRE, R. "Guadalajara y su región: cambios y permanencias en la relación religión-cultura-territorio”. En Karla Covarrubias (Comp.), Cambios religiosos globales y reacomodos locales. Universidad de Colima/Universidad de Aguascalientes, Colima, México. 2002

DE LA TORRE, R. y F. GUZMÁN. "Santo Toribio. De mártir de los Altos a santo de los emigrantes." Revista Estudios del Hombre. Vol. 25, p. 107-127. 2010

FÁBREGAS, A. Formación histórica de una región: Los Altos de Jalisco. CIESAS, México, D.F. 1986 aumento de las escalas de movilidad.

GÁLVEZ, MA. "San Juan de los Lagos: de la advocación a la feria". En Estudios Jaliscienses. El Colegio de Jalisco. Zapopan, Jalisco. México. 1996

GODOY, J. Representaciones y contradicciones: la ambivalencia hacia las imágenes, el teatro, la ficción, las reliquias y la sexualidad. Barcelona, Paidós. 1999

GONZÁLEZ M., F. Matar y morir por Cristo Rey. Aspectos de la cristiada. Instituto de Investigaciones Sociales de la UNAM y Plaza y Váldez, México. 2001

GUZMÁN M., F. Santo Toribio Romo: Un símbolo polisémico. Tesis de Maestría, CIESAS, Occidente. Guadalajara, Jalisco, México. 2002

HIRAI, S. Economía Política de la Nostalgia: Un estudio sobre la transformación del paisaje urbano en la migración trasnacional entre México y Estados Unidos. UAM-Iztapalapa, México. 2009

MEDINA G. C. Impacto territorial del turismo religioso en Santa Ana de Guadalupe, Jalisco. Tesis de licenciatura. Universidad Nacional Autónoma de México. Distrito Federal, México. 2011

OROZCO, J. El negocio de los ilegales: ganancias para quién. Instituto Libre de Filosofía; Guadalajara, México. 1992

PRESTON, J. "Spiritual magnetism: an organizing principle for the study of pilgrimage". In Morinis, A. Sacred Journeys: The Anthropology of pilgrimage._Greenwood Press. Westport, Connecticut. London. 1992

ROMO, R. Santo Toribio Romo. Biografía completa del santo. 2000

RUBIAL, A. "Cristianismo-paganismo. La Iglesia ante la religiosidad popular en la Edad Media y el Renacimiento". En De la Garza, M. y Ma. Del C. Valverde (coordinadores) Teoría e historia de las religiones. Colección seminarios, Facultad de Filosofía y Letras, UNAM. México. 1998

STODDARD, R. "Defining and Classifying Pilgrimages". In Sttodard, R. and A. Morinis (Ed). Sacred Places, Sacred Spaces: The Geography of Pilgrimage. GEOSCIENCE AND MAN, vol. 34. Geoscience Publications, Department of Geography and Anthropology. Lousiana State University. Baton Rouge, L.A. USA. 1997

VUKONIC, B. Tourism and religion. Ed. Pergamon. University of Zagreb. 1996

Referencia electrónica

[1] www.santotoribioromo.com 


\title{
MAGNETISMO ESPIRITUAL: TORIBIO ROMO SUS RELIQUIAS Y LA EXPANSIÓN TERRITORIAL DEL CULTO.
}

\begin{abstract}
Resumo: A introdução do culto das relíquias e aos santos pelo colonialismo espanhol, trouxe um modelo de determinada crença no Vice-Reino da Nova Espanha, que neste período era formação do que hoje é identificado como o México. No caso da região de Altos de Jalisco, localizado a oeste do país, a Igreja Católica desempenhou um papel fundamental na composição sociocultural da população, lhe dando uma identidade que é diferente de outras áreas e regiões do país. Na sequência da Revolução Mexicana (19101921), ocorre um levantamento de uma série de leis anticlericais que reconhecem a superioridade legal do Estado sobre a Igreja. Esse fato levou a um conflito entre as instituições, que terminou em um levante armado pelo povo de Los Altos de Jalisco e centro-oeste do México, neste período (1926-1929), levanta-se uma série de cultos populares, que destaca Toribio Romo, um sacerdote morto durante o conflito e a população local que obteve as relíquias para veneração; anos após a instituição católica dá a categoria de santo no ano 2000. Após isso, o aumento da convergência de peregrinos / devotos para a cidade de Santa Ana de Guadalupe, para a veneração das relíquias, têm crescido em escalas geográficas, saindo de uma escala local para a internacional, por causa da alta taxa de migração para os Estados Unidos.
\end{abstract}

Palavras-chave: magnetismo espiritual, relíquias, Santos, Toribio Romo. 